\title{
Success factors of lean six sigma implementation in manufacturing
}

\author{
Nejah Ben Mabrouk ${ }^{\mathrm{a}}$, Saber Ibrahim ${ }^{\mathrm{a}}$ and Mansour Eddaly ${ }^{\mathrm{a}^{*}}$
}

${ }^{a}$ Department of Management Information Systems and Producion Management, College of Business and Economics, Qassim University, P.O. Box 6640, Buraidah, 51452, Qassim, Saudi Arabia

\section{H R O N I C L E}

\begin{tabular}{l}
\hline Article history: \\
Received April 15, 2020 \\
Received in revised format June \\
8,2020 \\
Accepted July 272020 \\
Available online \\
July 272020 \\
\hline Keywords: \\
Lean six sigma \\
Manufacturing \\
Success factors \\
Interpretive structural \\
modeling \\
\hline
\end{tabular}

\section{A B S T R A C T}

Recently, Lean Six Sigma (LSS) has attracted much attention from both researchers and practitioners. In fact, many published papers used a quantitative research methodology to build and test theory in the field of LSS implementation in manufacturing area. Very few studies have been reported about the critical success factors influencing of six sigma implementations. The aim of this study is to present the results, from an empirical evidence, of Six Sigma implementation in Tunisian manufacturing. Therefore, fourteen main factors have been identified through literature review and questionnaire survey. Interpretive structural modeling (ISM) has been used to develop a hierarchical structure for analyzing the interactions among the key factors. By using the MICMAC technique, the barriers were classified into four groups according to their driving power and dependence power. Our finding provides important insight to managers and practitioners about factors in the LSS implementation process.

(C) 2021 by the authors; license Growing Science, Canada.

\section{Introduction}

Lean Six Sigma is considered as a business strategy adopted by companies to ensure the quality improvement within organization. The implementation of this concept was first developed by Motorola in the 1980s. Since, large multinational companies such as General Electric, Allied Signal, Texas Instrument, Sony and others firms have implemented it successfully in order to assure the growth of customer expectations and to reduce the unnecessary wastes and production costs. Kwak and Anbari (2006), Snee (2010) and Wilson (2009) confirmed that applying lean or Six Sigma or both methods implies the progression of performance in many organizations by reducing costs, improving productivity and reducing their cycle times. However, Coronado and Antony (2002) stated that, not all firms can reach the same benefits. These findings make Six Sigma implementation a fundamental process, where the success factors must be recognized primarily. During the implementation, some techniques and tools are required to be used such as statistical process controls and DMAIC (Define-Measure-Analyze-Improve-Control) technique with the support of top management (Breyfogle 2003). The objective becomes to improve the performance of the implementation of Six Sigma method considering the elimination of the existing defects and variability in the business processes. Byrne (2003) stated that many companies that adopt the Six Sigma method are failing because they have not established the suitable key elements to guarantee their success. Oke (2012) noted that it was important to understand the features and limitations of the Six Sigma method, which allows managers to better control their strategic orientations, coaching and training needs. Therefore, this study presents a framework of the different key success factors used during the implementation of six sigma program. This permits to managers to guarantee their organizations performance depending on their organizational needs. The aim of this paper is to identify and propose a framework of the key factors required for a successful implementation of lean six sigma methodology. First, a summary of literature review of the utilization of critical success factors of lean six sigma during the last years is presented in the second section. Then, factors are cited and discussed in section three. Moreover, we presented our proposed methodology of

* Corresponding author Tel.: +966557713347

E-mail address: eddaly.mansour@gmail.com (M. Eddaly)

C 2021 by the authors; licensee Growing Science.

doi: $10.5267 /$ j.uscm.2020.7.008 
implementation of the six sigma program in section four. Then, in section five, we presented the findings of the proposed methodology and the results are discussed underlying comparisons between lean six sigma key factors used in literature. Finally, conclusions and future researches are presented in the last section.

\subsection{Research Gaps}

In a Global, increasingly open, integrated, and borderless international economy, the Tunisian enterprises should apply different quality programs, especially LSS, to be more competitive. In the beginning, LSS and SS are implemented within large companies but, over time, even the small and medium enterprises feel a need for this implementation. Besides, the employment of LSS and SS requires some of factors associated with the size and availability of the resources. Even though, much attention is addressed to the LSS and SS implementation field, but less research work has been carried out using an interpretive structural modeling (ISM) approach. Hence, in the present purpose, a novel research of identifying and modeling the critical key factors for the LSS in the Tunisian SMEs has been performed. The aim of this study is to examine the critical success factors that condition successfulness of LSS implementation in manufacturing for SMEs.

\section{Literature survey and factors identification}

Lean Six Sigma methodology is adopted and applied in many organizations. Today, it is not considered as a new concept for quality improvement in terms of providing benefits to manufacturing and industrial firms. The objective is to formulate a structured framework and a strong managerial support which guarantee a successful performance implementation within these organizations. The combination of Lean and Six Sigma methodologies have been cited in several works because together, they provide the necessary tools to achieve improvements with effective results even significantly better than that the expected if theywere applied alone (Smith 2003). Some authors considered that applying Lean and Six Sigma separately is not efficient such as Harrison (2006). Others confirmed the benefits of combining Lean and Six Sigma methodologies like Koning et al. (2006). When the LSS program is adopted, it is vital to start by identifying success factors for organizations and the variables that could influence the results of the methodology. In literature, authors observed several success factors for Six Sigma that have been presented underlying their important role in successful implementation of Six Sigma such as the works of Antony and Banuelas (2002), Coronado and Antony (2002), Antony et al. (2005), Kwak and Anbari (2006), Antony (2011), Snee (2010), Brun (2011), Zailani and Sasthriyar (2011) and Prieto-avalos et al. (2014). Once these factors are taken into consideration, the organization will follow the appropriate way of implementing six sigma. The known factors in literature are essentially top management involvement and commitment, education and training, skills, communication process, linking Six Sigma to suppliers, linking Six Sigma to customer, cultural change, rewards and understanding the tools and techniques. The findings of the six sigma program cannot be successful in all cases. Some fails are mentioned in the literature during the last years. Studies that are developed and admitted the benefits of applying six sigma methodology in many fields are presented in different ways. Zailani and Sasthriyar (2011) cited that Six Sigma method plays a primordial role to solve problems and ensure good quality of service. Wang et al. (2004), Knowles et al. (2005) and Chappell and Peck (2006) studied whether the Six-Sigma methodology is applied usefully to measure and improve the performance of the whole supply network. In the same context, Wang et al. (2004) provided an application guideline for the improvement and the control of quality in supply chain management for some suppliers of a PC manufacturer. In addition, several organizations obtained results having gaps between the six sigma success and operational performance which indicates that reaching the objective of success implementation must be maintained by a managerial support which defines the essential critical factors during the six sigma process. Several works on key success factors of lean six sigma uses in manufacturing services showed that there is a part of firms that failed to reach success in their implementation process.

Zailani and Sasthriyar (2011) studied the relationship between the critical factors for the implementation of Six-Sigma programs in Malaysia.Hamid (2011), Jayaraman et al. (2012) criticized the way that firms have to follow in order to reach the desired objective. Jeyaraman and Teo (2010) and Gorantiwar and Shrivastava (2014) stated that it is crucial to define the key success factors of lean six sigma implementation in relation with its operational performance and organizational performance. Psychogios et al. (2012) presented that important difficulties that slow down the implementation process, such as, absence of consciousness for lean six sigma, absence of consciousness for the necessity of continuous quality improvement programs, absence of strategic policies and working personality. These factors have to be considered as powerful force to the success of lean implementation including comprehensive training programs, teamwork and top management commitment (Piercy and Rich 2009). Experts agreed that some key factors must be identified and taken into account when applying the Six Sigma program in any company in order to guarantee the success of its implementation. Coronado and Antony (2002) and Antony and Banuelas (2002) stated that attention must be drawn to the critical ingredients of Six Sigma in order to have a successive implementation. In this section, we outline the necessary critical factors leading to a successful six sigma project. It is essential to identify the weights of these factors and the relationship between them based on previous studies such as the works of Pande et al. (2000), Henderson and Evans (2000), Eckes (2001), and Antony and Banuelas (2002). Based on various works dealing with the adoption of lean six sigma method, we record, in what follows, the most important of these factors.

\subsection{Management involvement and commitment}

It is considered as the important key of success for a six sigma program. It is based on the fact that the top management and the participation of leadership in all stages implies better implementation. Harry and Schroeder (2005) stated that managers should make a serious commitment during the Six Sigma procedure. Laureani and Antony (2012) indicated that any 
successful initiative program such as Six Sigma needs top management involvement and provision of appropriate resources and training. Six sigma requires the optimal use of resources and efforts of top management in order to restructure the business procedures. Without serious management involvement and commitment, the outcomes of the program will be in doubt (Pande et al. 2000). Management involvement is strongly related to the quality, performance and the implementation of six sigma programs. Under such conditions, employees change their attitudes and contribute efficiently to establish their required tasks. Thus, a successful Six Sigma is reached when the organization guarantees the optimal allocation of resources, workforce, effort, time and money.

\subsection{Cultural change}

Once the organization adopted the idea of a six sigma program, top managers will introduce new ideas and methodologies within an organization. Thus, employees will be invited to stand by all changes. They must understand their need for change (Albliwi et al., 2015). Zailani and Sasthriyar (2011) studied the relationship between the key factors in some electronic companies in Malaysia and they revealed that cultural change was the highest variable. Necessary education rules are provided to employees progressively which leads to the development of the organization in several areas. In order to reach the desired success, top management leaders introduce cultural changes positively by the creation of knowledge management concept, overcoming resistance, following an efficient communication plan, motivating and monitoring during the six sigma implementation. Chakraborty and Tan (2007) stated that the company must accept that Six Sigma is an agent of change and its culture and values must adjust consequently. Thus, people facing this cultural change and challenges must understand this requirement.

\subsection{Communication}

Six Sigma is an approach that focuses on the quality of the planned projects. Thus, higher levels of communication are required for the successful implementation of its program. This was confirmed by Coronado and Antony (2002) and Ho et al. (2008). Since Six sigma includes the organizational infrastructure, employees should communicate with a unified language (Antony, 2006, Henderson \& Evans, 2000). For this reason, the lean six sigma may require strong communication networks to be established. Therefore, it is recommended that one of the important priority of the organization is to give a degree of communication between the employees understanding their objectives and respecting the basic rules of both their responsibilities and roles.

\subsection{Linking Six Sigma to business strategy}

The Six Sigma methodology must be strongly linked to the strategy implemented by the organization defining appropriately any action or decision. Pande et al. (2000) states that It needs to be clear how Six Sigma projects and other activities are related to customers, core processes and competitiveness. Since any organization has as primordial objective making benefits, Six Sigma projects improve the business processes by facing variability which leads to high defect rate, high rework rate, low productivity, etc. (Antony \& Banuelas 2002).

\subsection{Linking Six Sigma to human resources}

In practice, it is evident that human resources have a major influence on the results of implementation of Lean Six Sigma through their actions and behavior (Zailani and Sasthriyar 2011, Shah and Ward 2003, Brun 2011). It is necessary to link human resources to Six Sigma in order to reach the expected synergy and collectivity between employees towards the accomplishment of organizational goals. Henderson and Evans (2000), Antony and Banuelas (2002) andWyper and Harrison (2000) stated that linking this methodology to human resources will ease the implementation and culture change, sustain the result and achieve a respectable behavior from the employees and concerned human resources associated with the organization.

\subsection{Education and training}

Several authors considered education and training as one of success factors of six sigma program such as Henderson and Evans (2000), Kwak and Anbari (2006) and Brun (2011). It is important for employees to understand the fundamentals of this technique in order to adopt it and apply it effectively. Top managers should apply an appropriate and continuous training system that leads to an optimal structured pyramid within an organization. George (2002) described the structure of training that should be applied within any organization like master black belt, black belts and green belt that collaborate to guarantee the increase of company performance. Also, Ingle and Roe (2001) stated that the employees have to fill out an application form to demonstrate how they succeeded training and practice of Six Sigma.

\subsection{Reward and recognition system}

This tool is performed by motivating employees in order to improve the global productivity within an organization. According to Antony et al. (2014), the development of a reward system has a direct influence on the outcome of a LSS project. Employees are rewarded in different ways and the rate of recognition is important in terms of promoting certain morals. Ahlstrom (1998), Scherrer et al. (2009) and Ho et al. (2008) stated that it is essential to ensure that the organization is able to effectively implement LSS and admitted that reward and recognition system encourage the employees to participate in projects that lead to improve quality and sustain results. 


\subsection{Organization infrastructure}

An optimal assignment of employees to the right tasks is required during the six sigma program implementation. Henderson and Evans (2000) illustrated in their findings that organizational infrastructure is an important factor for the success of implementation of LSS. It is also important to take into account the requirements related to the software support and the information technology used for obtaining high quality of the six sigma program. As Harry and Schroeder (2005) described, organizational infrastructure should be functional in any organization starting from the top managers, the champions, followed by the formation of master black belts, black belts, green belts and other team members who are individuals who support specific projects in their area.

\subsection{Linking Six Sigma to the customer}

This factor is mentioned in several papers and it is important while implementing six sigma projects (Harry and Schroeder 2005, Pande et al. 2000). The customers' behavior should be studied properly and linked to six sigma projects. Antony and Banuelas (2002) divided this factor into two steps: the first one includes identifying the core process, the key outputs of these processes and the variation of costs or profits and the second one includes identifying and defining the customer needs, requirements, and expectation.

\subsection{Linking Six Sigma to suppliers}

This factor includes identifying the long-term relationship between the organization and suppliers to ensure the quality of goods and services. Several authors suggested to maintain a small number of suppliers and link such as Harry (1998) and Harry and Schroeder (2005). It is advisable to maintain small supplier base because it improves product quality and productivity of buyers by encouraging enhanced supplier commitment to product design and quality. Also, Henderson and Evans (2000) suggested that linking Six-Sigma strategy to a small number of suppliers helps to improve the quality and avoids the delivery problems. Effective Linkage motivates suppliers to become partners in the buying strategy of the firm. They can also help purchasers to procure the materials and parts that can be used most efficiently (Sandholm and Sorqvist 2002).

\subsection{Understanding tools and techniques of six sigma methodology}

Employees are invited to understand and apply the instructions of six sigma procedure during their training. In this way, they can innovate and find new techniques of improvement. Choo et al. (2007) stated that, to be effective, training in quality subjects should underline the techniques of problem solving, effective communication, and statistical process control. Also, Eckes (2001) and Ingle and Roe (2001) confirmed that sustaining improvement effort within an organization requires the continuity of workforce training in tools and techniques. Thus, it helps employees to be effective participants in the improvement of the organization.

\subsection{Project management skills}

It is used as a beneficial factor for the success of Six Sigma methodology by several authors such as Kwak and Anbari (2006), Brun (2011) and Antony and Banuelas (2002). To make Six sigma projects successful, it is important to define the number of the black belts and then the master black belts. This task must be selective to reach a high level quality at the end of each project. According to Antony and Banuelas (2002), team members must have project management skills in order to meet the deadlines and milestones. Eckes (2001) confirmed that one of the reasons of the failure in Six Sigma projects are the poor project management.

\subsection{Project prioritization and selection}

According to Sandholm and Sorqvist (2002), the prioritization and selection of projects must be selected, evaluated, and improved during the Six-Sigma implementation. This factor is required in the organization because unsuccessful selected and defined projects may cause delayed results and high risk of blocking (Pande et al. 2000). Some previous works showed that in the back belt training program, project team leader and members should learn tools and techniques in effective project management (Eckes 2001).

\subsection{Involvement of employees}

Zakuan et al. (2010) stated that companies are considering that employee involvement is critical to reach better quality performance. Lyons et al. (2011) considered that employee should be involved in order to establish a common workforce understanding about what is to be achieved at an organization level. With this way, organizational objectives become associated with the employees fixed measures, their skills, and their development plans.

\section{Research methodology}

\subsection{Data collection}

Data used in this paper were collected through a questionnaire survey to examine the relationship between the listed factors of six sigma implementation. A questionnaire was prepared covering the 14 CSFs as illustrated in Table 1. From 120 
distributed questionnaires, we received feedback from 84 (70\%) respondents. The demographics analysis of the questionnaires provided the flowing results: The distribution of the sample of enterprises according to the number of employees is given by : The major part of enterprises had between 50 and 150 employees $(71.42 \%), 19.04 \%$ of enterprises responded had between 150 and 250 employees and $9.52 \%$ had less than 50 employees. For the position occupied by the respondents: Project Champions (7.14\%), black belts (47.6\%), and (45.23\%) for green belts or yellow belts who have firsthand knowledge and expertise with the six sigma program. Concerning the type of industries participated in this study is distributed as follow:36 respondents from textiles (42.85\%), 28 in food-processing (33.33\%) and 20 in plastics (23.8\%). The reliability of the questionnaires confirmed based on calculation of Cronbach's alpha coefficient, which for all factors in this study was larger than 0.7 , indicating an acceptable level of reliability of the factors.

\subsection{ISM methodology}

ISM uses an interpretive approach (based on the judgments of the experts from the industry and academia) for identifying and summarizing the contextual relationship among the different and directly related identified factors of an issue or a problem (Sage 1977; Warfield 1974). This methodology is widely used by researchers for exploring direct and indirect association among the identified variables of various fields in a simplified way. In fact, ISM has been applied successfully in a number of areas like green supply chain management (Ben Mabrouk, 2020; Ben Mabrouk et al., 2020; Majumdar \& Sinha, 2019; Agi \& Nishant 2017 ), sustainable supply chain (Shibin et al., 2017; Hussain et al., 2016), third party logistics (Govindan et al., 2012), cloud computing adoption (Raut et al., 2017), Risk Management of Supply chain (Sajid et al. 2017). The various steps involved in the ISM technique are illustrated as follow:

- $\quad$ Step 1: Factors for the system under consideration are listed;

- Step 2: Contextual relationship is established among factors with respect to which pairs of factors would be examined;

- Step 3: A Structural Self-Interaction Matrix (SSIM) is developed for factors, which indicates pairwise relationships among factors of the system under consideration;

- $\quad$ Step 4: Construct the Initial Reachability Matrix (IRM) and the Final Reachability Matrix (FRM);

- Step 5: Partitioning of reachability matrix into different levels;

- Step 6: A digraph is drawn and the transitive links are removed based on the relationship given in the above reachability matrix;

- Step 7: Converting the resultant digraph into an ISM by replacing element nodes with statements;

- Step 8: Reviewing the ISM model to check for conceptual inconsistency, and making the necessary modifications.

The general framework of the ISM procedure is given in Fig. 1.

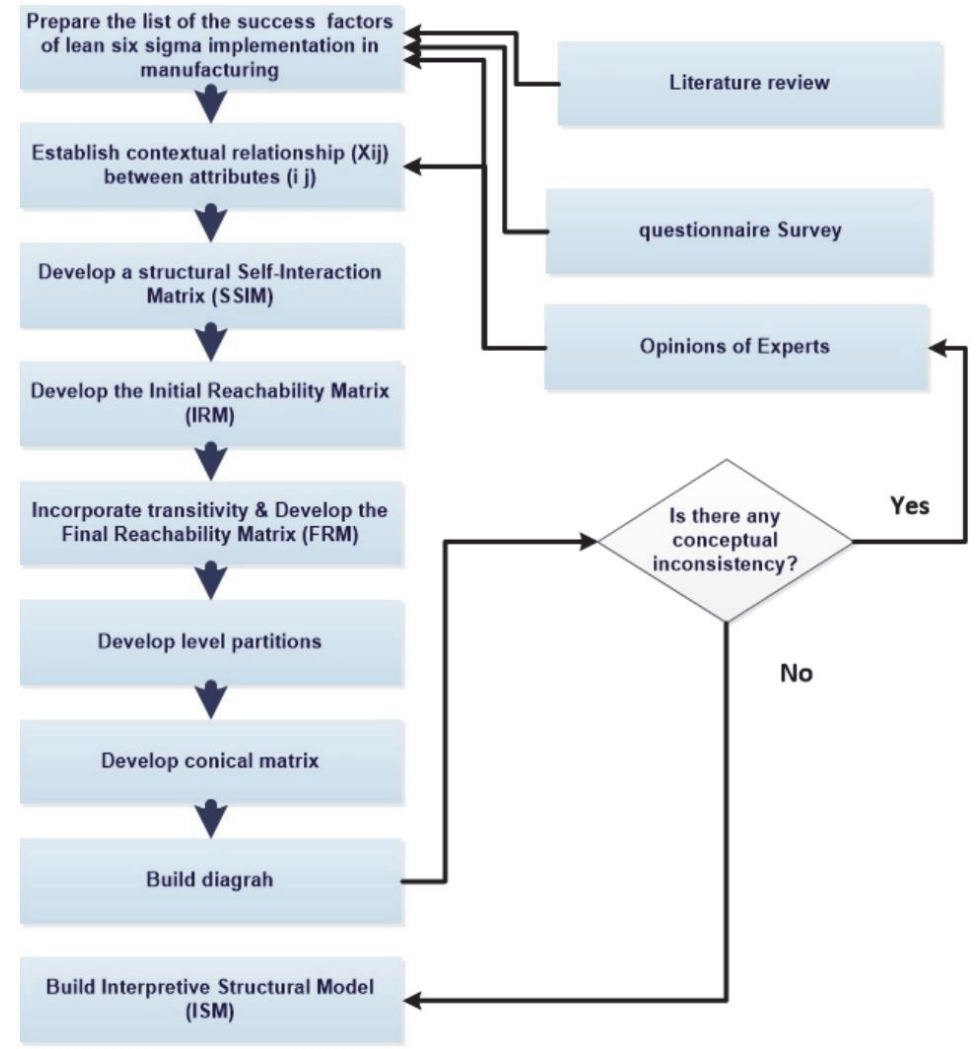

Fig. 1. Interpretive Structural Model framework 
A set of fourteen factors were identified from an extensive literature survey of past research studies for the LSS implementation in the manufacturing context (Table 1). The feed-back of the experts among the mentioned questionnaire are strongly aligned with the factors identified from the literature survey.

\section{Development of Structural Self-Interaction matrix (SSIM)}

The SSIM is formulated from the interrelationship among the fourteen critical factors presented in Table1, which indicates the pairwise relationship between elements of the system. Four symbols $(V, A, X$ and $O)$ were used for denoting the relationship between factors $i$ and $j$. $V$ : Factor $i$ will lead to factor $j$ and not in both directions; $A$ : Factor $j$ will lead to factor $i$ but not in both directions; $X$ : Factor $i$ and $j$ will lead to each other; $O$ : no relation between the factors (Table 2).

\section{Reachability Matrix}

The initial reachability matrix (IRM) is developed from SSIM as shown in Table 3 using the following rules: If the ( $i, j$ ) entry of SSIM is $V$, then $(i, j)$ and $(j, i)$ entries in the reachability matrix are equal to 1 and 0 , respectively. If the $(i, j)$ entry of SSIM is $A$, then $(i, j)$ and $(j, i)$ entries in the reachability matrix are equal to 0 and 1 , respectively.

If the $(i, j)$ entry of SSIM is $X$, then $(i, j)$ and $(j, i)$ entries in the reachability matrix are both equal to 1 . If the $(i, j)$ entry of SSIM is $O$, then $(i, j)$ and $(j, i)$ entries in the reachability matrix are both equal to 0 .

The final reachability matrix (FRM) is obtained from the initial reachability matrix by adding transitivity. The transitivity of the contextual relation is a basic assumption made in ISM, which states that if the variable A is related to $\mathrm{B}$ and $\mathrm{B}$ is related to $C$, then $A$ is necessarily related to $C$, where entry $(A, B)$ should be equal to 1 in the $F R M$, otherwise $(A, B)=0$ (Malone 1975). From the IRM, we can obtain the final reachability matrix (FRM) by applying the following Boolean algorithm: $0+0=1 ; 0+1=1 ; 1+0=1 ; 1+1=1$ and $0 \times 0=1 ; 0+1=0 ; 1 \times 0=0 ; 1 \times 1=1$. FRM $=(\operatorname{IRM}+\mathrm{I})^{n}, n>1$.

Where: IRM is the initial reachability matrix, I is the identity matrix of ordern. By using the Boolean algorithm, FRM = $(I R M+I)^{n}=I+I R M+I^{2} M^{2}+\ldots+I^{2} M^{n}$ (Shen et al. 2016). The dependence and driving power of each factor is also indicated as shown in Table 4. These driving power and dependencies are then used in the MICMAC analysis.

\section{Table 1}

Factors influencing LSS implementation

\begin{tabular}{|c|c|c|}
\hline No & Factors & References \\
\hline 1 & $\begin{array}{l}\text { Management involvement and } \\
\text { commitment }\end{array}$ & Harry and Schroeder (2005), Pande et al. (2000), Laureani and Antony (2012) \\
\hline 2 & Cultural change & Chakraborty and Tan (2007), Zailani and Sasthriyar (2011), Albliwi et al. (2015) \\
\hline 3 & Communication & $\begin{array}{l}\text { Henderson and Evans (2000), Coronado and Antony (2002), Ho et al. (2008), Antony } \\
\text { (2006) }\end{array}$ \\
\hline 4 & Organization infrastructure & Harry and Schroeder (2005), Henderson and Evans (2000) \\
\hline 5 & Education and training & $\begin{array}{l}\text { Henderson and Evans (2000), Ingle and Roe (2001), George (2002), Kwak and } \\
\text { Anbari (2006), Brun (2011) }\end{array}$ \\
\hline 6 & Involvement of employees & Zakuan et al. (2010), Lyons et al. (2011) \\
\hline 7 & Reward and recognition system & Ahlstrom (1998), Scherrer et al. (2009), Ho et al. (2008) \\
\hline 8 & Linking Six Sigma to business strategy & Pande et al. (2000) Antony and Banuelas (2002) \\
\hline 9 & Linking Six Sigma to the customer & $\begin{array}{l}\text { Harry and Schroeder (2005), Pande et al. (2000), } \\
\text { Antony and Banuelas (2002) }\end{array}$ \\
\hline 10 & Linking Six Sigma to human resources & $\begin{array}{l}\text { Henderson and Evans (2000), Wyper and Harrison (2000), Antony and Banuelas } \\
\text { (2002), Shah and Ward (2003), Brun (2011), Zailani and Sasthriyar (2011) }\end{array}$ \\
\hline 11 & Linking Six Sigma to suppliers & $\begin{array}{l}\text { Harry (1998), Harry and Schroeder (2005), Henderson and Evans (2000), Sandholm } \\
\text { and Sorqvist (2002) }\end{array}$ \\
\hline 12 & Understanding its tools and techniques & Eckes (2001), Laureani and Antony (2012), Ingle and Roe (2001), Choo et al. (2007) \\
\hline 13 & Project management skills & Antony and Banuelas (2002), Kwak and Anbari (2006), Brun (2011), Eckes (2001) \\
\hline 14 & Project prioritization and selection & Eckes (2001), Pande et al. (2000), Sandholm and Sorqvist (2002) \\
\hline
\end{tabular}

\section{Level partition}

From the FRM, the reachability, antecedent and the intersection sets for factors are obtained. The reachability set of an individual factor comprises of other elements and itself, which it may help to achieve. A concerned factor's reachable factors are those factors with the value of 1 in the row corresponding to the concerned factor in the FRM (Table 5). Whereas the antecedent set includes of the factors themselves and the other factors, which may this may help in achieving it. A concerned factor's reached factors are those factors with the value of 1 in the column corresponding to the concerned factor in the FRM (Table 5). Afterward, the intersection of these sets is obtained for all the critical factors. The factors that show the same place of reachability and intersection sets are located at the top level of the ISM hierarchy. This element is driven by all other factors and does not affect elements. The element represented in the top level are removed and this procedure is iteratively repeated until factors at all levels are determined (Table 6 and 7). 
Table 2

Structural self-interaction matrix (SSIM)

\begin{tabular}{cllllllllllllll}
\hline No. & $\mathbf{1}$ & $\mathbf{2}$ & $\mathbf{3}$ & $\mathbf{4}$ & $\mathbf{5}$ & $\mathbf{6}$ & $\mathbf{7}$ & $\mathbf{8}$ & $\mathbf{9}$ & $\mathbf{1 0}$ & $\mathbf{1 1}$ & $\mathbf{1 2}$ & $\mathbf{1 3}$ & $\mathbf{1 4}$ \\
\hline $\mathbf{1}$ & $X$ & $V$ & $X$ & $V$ & $X$ & $A$ & $A$ & $V$ & $X$ & $V$ & $X$ & $O$ & $O$ & $V$ \\
$\mathbf{2}$ & & $X$ & $X$ & $O$ & $A$ & $X$ & $A$ & $A$ & $A$ & $A$ & $A$ & $A$ & $O$ & $A$ \\
$\mathbf{3}$ & & & $X$ & $V$ & $A$ & $O$ & $O$ & $V$ & $X$ & $X$ & $X$ & $A$ & $A$ & $X$ \\
$\mathbf{4}$ & & & & $X$ & $O$ & $X$ & $O$ & $A$ & $A$ & $A$ & $A$ & $O$ & $O$ & $A$ \\
$\mathbf{5}$ & & & & & $X$ & $X$ & $V$ & $A$ & $A$ & $A$ & $A$ & $V$ & $V$ & $O$ \\
$\mathbf{6}$ & & & & & & $X$ & $X$ & $A$ & $O$ & $X$ & $A$ & $O$ & $A$ & $O$ \\
$\mathbf{7}$ & & & & & & & $X$ & $A$ & $O$ & $A$ & $O$ & $O$ & $A$ & $O$ \\
$\mathbf{8}$ & & & & & & & & $X$ & $X$ & $X$ & $X$ & $V$ & $V$ & $X$ \\
$\mathbf{9}$ & & & & & & & & & $X$ & $X$ & $X$ & $V$ & $V$ & $X$ \\
$\mathbf{1 0}$ & & & & & & & & & & $X$ & $X$ & $X$ & $V$ & $A$ \\
$\mathbf{1 1}$ & & & & & & & & & & & $X$ & $X$ & $V$ & $X$ \\
$\mathbf{1 2}$ & & & & & & & & & & & & $X$ & $V$ & $V$ \\
$\mathbf{1 3}$ & & & & & & & & & & & & $X$ & $O$ \\
$\mathbf{1 4}$ & & & & & & & & & & & & $X$ \\
\hline
\end{tabular}

Table 3

Initial reachability matrix (IRM)

\begin{tabular}{ccccccccccccccc}
\hline No. & $\mathbf{1}$ & $\mathbf{2}$ & $\mathbf{3}$ & $\mathbf{4}$ & $\mathbf{5}$ & $\mathbf{6}$ & $\mathbf{7}$ & $\mathbf{8}$ & $\mathbf{9}$ & $\mathbf{1 0}$ & $\mathbf{1 1}$ & $\mathbf{1 2}$ & $\mathbf{1 3}$ & $\mathbf{1 4}$ \\
\hline $\mathbf{1}$ & 1 & 1 & 1 & 1 & 1 & 0 & 0 & 1 & 1 & 1 & 1 & 0 & 0 & 1 \\
$\mathbf{2}$ & 0 & 1 & 1 & 0 & 0 & 1 & 0 & 0 & 0 & 0 & 0 & 0 & 0 & 0 \\
$\mathbf{3}$ & 1 & 1 & 1 & 1 & 0 & 0 & 0 & 1 & 1 & 1 & 1 & 0 & 0 & 1 \\
$\mathbf{4}$ & 0 & 0 & 0 & 1 & 0 & 1 & 0 & 0 & 0 & 0 & 0 & 0 & 0 & 0 \\
$\mathbf{5}$ & 1 & 1 & 1 & 0 & 1 & 1 & 1 & 0 & 0 & 0 & 0 & 1 & 1 & 0 \\
$\mathbf{6}$ & 1 & 1 & 0 & 1 & 1 & 1 & 1 & 0 & 0 & 1 & 0 & 0 & 0 & 0 \\
$\mathbf{7}$ & 1 & 1 & 0 & 0 & 0 & 1 & 1 & 0 & 0 & 0 & 0 & 0 & 0 & 0 \\
$\mathbf{8}$ & 0 & 1 & 0 & 1 & 1 & 1 & 1 & 1 & 1 & 1 & 1 & 1 & 1 & 1 \\
$\mathbf{9}$ & 1 & 1 & 1 & 1 & 1 & 0 & 0 & 1 & 1 & 1 & 1 & 1 & 1 & 1 \\
$\mathbf{1 0}$ & 0 & 1 & 1 & 1 & 1 & 1 & 1 & 1 & 1 & 1 & 1 & 1 & 1 & 0 \\
$\mathbf{1 1}$ & 1 & 1 & 1 & 1 & 1 & 1 & 0 & 1 & 1 & 1 & 1 & 1 & 1 & 1 \\
$\mathbf{1 2}$ & 0 & 1 & 1 & 0 & 0 & 0 & 0 & 0 & 0 & 1 & 1 & 1 & 1 & 1 \\
$\mathbf{1 3}$ & 0 & 0 & 1 & 0 & 0 & 1 & 1 & 0 & 0 & 0 & 0 & 0 & 1 & 0 \\
$\mathbf{1 4}$ & 0 & 1 & 1 & 1 & 0 & 0 & 0 & 1 & 1 & 1 & 1 & 0 & 0 \\
\hline
\end{tabular}

Table 4

Final reachability matrix (FRM)

\begin{tabular}{|c|c|c|c|c|c|c|c|c|c|c|c|c|c|c|c|}
\hline No. & 1 & 2 & 3 & 4 & 5 & 6 & 7 & 8 & 9 & 10 & 11 & 12 & 13 & 14 & $\begin{array}{c}\text { Driving } \\
\text { power }\end{array}$ \\
\hline 1 & 1 & 1 & 1 & 1 & 1 & $1^{*}$ & $1^{*}$ & 1 & 1 & 1 & 1 & $1^{*}$ & $1^{*}$ & 1 & 14 \\
\hline 2 & $1^{*}$ & 1 & 1 & $1^{*}$ & $1^{*}$ & 1 & $1^{*}$ & $1^{*}$ & $1^{*}$ & $1^{*}$ & $1^{*}$ & 0 & 0 & $1^{*}$ & 12 \\
\hline 3 & 1 & 1 & 1 & 1 & $1^{*}$ & $1^{*}$ & $1^{*}$ & 1 & 1 & 1 & 1 & $1^{*}$ & $1^{*}$ & 1 & 14 \\
\hline 4 & $1^{*}$ & $1^{*}$ & 0 & 1 & $1^{*}$ & 1 & $1^{*}$ & 0 & 0 & $1^{*}$ & 0 & 0 & 0 & 0 & 7 \\
\hline 5 & 1 & 1 & 1 & $1^{*}$ & 1 & 1 & 1 & $1 *$ & $1^{*}$ & $1^{*}$ & $1^{*}$ & 1 & 1 & $1^{*}$ & 14 \\
\hline 6 & 1 & 1 & $1^{*}$ & 1 & 1 & 1 & 1 & $1 *$ & $1^{*}$ & 1 & 1 & $1^{*}$ & $1^{*}$ & $1^{*}$ & 14 \\
\hline 7 & 1 & 1 & $1^{*}$ & $1^{*}$ & $1^{*}$ & 1 & 1 & $1^{*}$ & $1^{*}$ & $1^{*}$ & $1^{*}$ & 0 & 0 & $1^{*}$ & 12 \\
\hline 8 & $1^{*}$ & 1 & 1 & 1 & 1 & 1 & 1 & 1 & 1 & 1 & 1 & 1 & 1 & 1 & 14 \\
\hline 9 & 1 & 1 & 1 & 1 & 1 & $1^{*}$ & $1^{*}$ & 1 & 1 & 1 & 1 & 1 & 1 & 1 & 14 \\
\hline 10 & $1^{*}$ & 1 & 1 & 1 & 1 & 1 & 1 & 1 & 1 & 1 & 1 & 1 & 1 & $1^{*}$ & 14 \\
\hline 11 & 1 & 1 & 1 & 1 & 1 & 1 & $1^{*}$ & 1 & 1 & 1 & 1 & 1 & 1 & 1 & 14 \\
\hline 12 & $1^{*}$ & 1 & 1 & $1^{*}$ & $1^{*}$ & $1^{*}$ & $1^{*}$ & $1^{*}$ & $1^{*}$ & 1 & 1 & 1 & 1 & 1 & 14 \\
\hline 13 & $1^{*}$ & $1^{*}$ & 1 & $1 *$ & $1^{*}$ & 1 & 1 & 1 * & $1^{*}$ & $1^{*}$ & $1^{*}$ & 0 & 1 & $1^{*}$ & 13 \\
\hline 14 & $1^{*}$ & 1 & 1 & 1 & $1^{*}$ & $1^{*}$ & $1^{*}$ & 1 & 1 & 1 & 1 & $1^{*}$ & $1^{*}$ & 1 & 14 \\
\hline $\begin{array}{c}\text { Dependence } \\
\text { Power }\end{array}$ & 14 & 14 & 13 & 14 & 14 & 14 & 14 & 13 & 13 & 14 & 13 & 10 & 11 & 13 & $184 / 184$ \\
\hline
\end{tabular}

${ }^{*}$ Represents transitivity property checked 
ISM model development

The structural model is constructed from the FRM. An arrow points from factor i to factor $\mathrm{j}$, showing that factor $\mathrm{i}$ can result in factor $\mathrm{j}$, and a two way arrow indicates a mutual influence.

\section{Table 5}

Level partitions (Iteration I)

\begin{tabular}{|c|c|c|c|c|}
\hline No. & Reachability set & Antecedent set & Intersection set & level \\
\hline 1 & $\begin{array}{l}\text { F1 F2 F3 F4 F5 F6 F7 F8 F9 } \\
\text { F10 F11 F12 F13 F14 }\end{array}$ & $\begin{array}{l}\text { F1 F2 F3 F4 F5 F6 F7 F8 F9 F10 } \\
\text { F11 F12 F13 F14 }\end{array}$ & $\begin{array}{l}\text { F1 F2 F3 F4 F5 F6 F7 F8 F9 } \\
\text { F10 F11 F12 F13 F14 }\end{array}$ & I \\
\hline 2 & $\begin{array}{l}\text { F1 F2 F3 F4 F5 F6 F7 F8 F9 } \\
\text { F10 F11 F14 }\end{array}$ & $\begin{array}{l}\text { F1 F2 F3 F4 F5 F6 F7 F8 F9 F10 } \\
\text { F11 F12 F13 F14 }\end{array}$ & $\begin{array}{l}\text { F1 F2 F3 F4 F5 F6 F7 F8 F9 } \\
\text { F10 F11 F14 }\end{array}$ & I \\
\hline 3 & $\begin{array}{l}\text { F1 F2 F3 F4 F5 F6 F7 F8 F9 } \\
\text { F10 F11F12 F13 F14 }\end{array}$ & $\begin{array}{l}\text { F1 F2 F3 F5 F6 F7 F8 F9 F10 } \\
\text { F11 F12 F13 F14 }\end{array}$ & $\begin{array}{l}\text { F1 F2 F3 F5 F6 F7 F8 F9 F10 } \\
\text { F11 F12 F13 F14 }\end{array}$ & \\
\hline 4 & F1 F2 F4 F5 F6 F7 F10 & $\begin{array}{l}\text { F1 F2 F3 F4 F5 F6 F7 F8 F9 F10 } \\
\text { F11 F12 F13 F14 }\end{array}$ & F1 F2 F4 F5 F6 F7 F10 & I \\
\hline 5 & $\begin{array}{l}\text { F1 F2 F3 F4 F5 F6 F7 F8 F9 } \\
\text { F10 F11 F12 F13 F14 }\end{array}$ & $\begin{array}{l}\text { F1 F2 F3 F4 F5 F6 F7 F8 F9 F10 } \\
\text { F11 F12 F13 F14 }\end{array}$ & $\begin{array}{l}\text { F1 F2 F3 F4 F5 F6 F7 F8 F9 } \\
\text { F10 F11 F12 F13 F14 }\end{array}$ & $\mathbf{I}$ \\
\hline 6 & $\begin{array}{l}\text { F1 F2 F3 F4 F5 F6 F7 F8 F9 } \\
\text { F10 F11 F12 F13 F14 }\end{array}$ & $\begin{array}{l}\text { F1 F2 F3 F4 F5 F6 F7 F8 F9 F10 } \\
\text { F11 F12 F13 F14 }\end{array}$ & $\begin{array}{l}\text { F1 F2 F3 F4 F5 F6 F7 F8 F9 } \\
\text { F10 F11 F12 F13 F14 }\end{array}$ & I \\
\hline 7 & $\begin{array}{l}\text { F1 F2 F3 F4 F5 F6 F7 F8 F9 } \\
\text { F10 F11 F14 }\end{array}$ & $\begin{array}{l}\text { F1 F2 F3 F4 F5 F6 F7 F8 F9 F10 } \\
\text { F11 F12 F13 F14 }\end{array}$ & $\begin{array}{l}\text { F1 F2 F3 F4 F5 F6 F7 F8 F9 } \\
\text { F10 F11 F14 }\end{array}$ & I \\
\hline 8 & $\begin{array}{l}\text { F1 F2 F3 F4 F5 F6 F7 F8 F9 } \\
\text { F10 F11 F12 F13 F14 }\end{array}$ & $\begin{array}{l}\text { F1 F2 F3 F5 F6 F7 F8 F9 F10 } \\
\text { F11 F12 F13 F14 }\end{array}$ & $\begin{array}{l}\text { F1 F2 F3 F5 F6 F7 F8 F9 F10 } \\
\text { F11 F12 F13 F14 }\end{array}$ & \\
\hline 9 & $\begin{array}{l}\text { F1 F2 F3 F4 F5 F6 F7 F8 F9 } \\
\text { F10 F11 F12 F13 F14 }\end{array}$ & $\begin{array}{l}\text { F1 F2 F3 F5 F6 F7 F8 F9 F10 } \\
\text { F11 F12 F13 F14 }\end{array}$ & $\begin{array}{l}\text { F1 F2 F3 F5 F6 F7 F8 F9 F10 } \\
\text { F11 F12 F13 F14 }\end{array}$ & \\
\hline 10 & $\begin{array}{l}\text { F1 F2 F3 F4 F5 F6 F7 F8 F9 } \\
\text { F10 F11 F12 F13 F14 }\end{array}$ & $\begin{array}{l}\text { F1 F2 F3 F4 F5 F6 F7 F8 F9 F10 } \\
\text { F11 F12 F13 F14 }\end{array}$ & $\begin{array}{l}\text { F1 F2 F3 F4 F5 F6 F7 F8 F9 } \\
\text { F10 F11 F12 F13 F14 }\end{array}$ & $\mathbf{I}$ \\
\hline 11 & $\begin{array}{l}\text { F1 F2 F3 F4 F5 F6 F7 F8 F9 } \\
\text { F10 F11 F12 F13 F14 }\end{array}$ & $\begin{array}{l}\text { F1 F2 F3 F5 F6 F7 F8 F9 F10 } \\
\text { F11 F12 F13 F14 }\end{array}$ & $\begin{array}{l}\text { F1 F2 F3 F5 F6 F7 F8 F9 F10 } \\
\text { F11 F12 F13 F14 }\end{array}$ & \\
\hline 12 & $\begin{array}{l}\text { F1 F2 F3 F4 F5 F6 F7 F8 F9 } \\
\text { F10 F11F12 F13 F14 }\end{array}$ & $\begin{array}{l}\text { F1 F3 F5 F6 F8 F9 F10 F11 F12 } \\
\text { F14 }\end{array}$ & $\begin{array}{l}\text { F1 F3 F5 F6 F8 F9 F10 F11 } \\
\text { F12 F14 }\end{array}$ & \\
\hline 13 & $\begin{array}{l}\text { F1 F2 F3 F4 F5 F6 F7 F8 F9 } \\
\text { F10 F11 F13 F14 }\end{array}$ & $\begin{array}{l}\text { F1 F3 F5 F6 F8 F9 F10 F11 F12 } \\
\text { F13 F14 }\end{array}$ & $\begin{array}{l}\text { F1 F3 F5 F6 F8 F9 F10 F11 } \\
\text { F13 F14 }\end{array}$ & \\
\hline 14 & $\begin{array}{l}\text { F1 F2 F3 F4 F5 F6 F7 F8 F9 } \\
\text { F10 F11F12 F13 F14 }\end{array}$ & $\begin{array}{l}\text { F1 F2 F3 F5 F6 F7 F8 F9 F10 } \\
\text { F11 F12 F13 F14 }\end{array}$ & $\begin{array}{l}\text { F1 F2 F3 F5 F6 F7 F8 F9 F10 } \\
\text { F11 F12 F13 F14 }\end{array}$ & \\
\hline
\end{tabular}

Table 6

Level partitions (Iteration II)

\begin{tabular}{lllll}
\hline No. & \multicolumn{1}{c}{ Reachability set } & \multicolumn{1}{c}{ Antecedent set } & \multicolumn{1}{c}{ Intersection set } & level \\
\hline $\mathbf{3}$ & F3 F8 F9 F11 F12 F13 F14 & F3 F8 F9 F11 F12 F13 F14 & F3 F8 F9 F11 F12 F13 F14 & II \\
$\mathbf{8}$ & F3 F8 F9 F11 F12 F13 F14 & F3 F8 F9 F11 F12 F13 F14 & F3 F8 F9 F11 F12 F13 F14 & II \\
$\mathbf{9}$ & F3 F8 F9 F11 F12 F13 F14 & F3 F8 F9 F11 F12 F13 F14 & F3 F8 F9 F11 F12 F13 F14 & II \\
$\mathbf{1 1}$ & F3 F8 F9 F11 F12 F13 F14 & F3 F8 F9 F11 F12 F13 F14 & F3 F8 F9 F11 F12 F13 F14 & II \\
$\mathbf{1 2}$ & F3 F8 F9 F11 F12 F13 F14 & F3 F8 F9 F11 F12 F14 & F3 F8 F9 F11 F12 F14 \\
$\mathbf{1 3}$ & F3 F8 F9 F11 F13 F14 & F3 F8 F9 F11 F12 F13 F14 & F3 F8 F9 F11 F13 F14 & II \\
$\mathbf{1 4}$ & F3 F8 F9 F11 F12 F13 F14 & F3 F8 F9 F11 F12 F13 F14 & F3 F8 F9 F11 F12 F13 F14 & II \\
\hline
\end{tabular}

Expelling the transitivity as depicted in the ISM procedure, the digraph is at last transformed into the ISM model as shown in figure (2). The fourteen factors were separated into three levels of the ISM model. This three-level structure is obtained from the level partition procedure provided by the relationships between factors illustrated in the final reachability matrix (FRM). It is not a general model, but it depends on the sample of the study. The obtained result confirms those of the previous studies in the literature that is all these 14 factors are critical for six sigma implementations (Brun 2011).

Table 7

Level partitions (Iteration III)

\begin{tabular}{lllllr}
\hline No. & Reachability set & & Antecedent set & Intersection set & level \\
\hline $\mathbf{1 2}$ & F12 & & F12 & & F12 \\
\end{tabular}

As seen in Fig. 2, this study checked the interactive relationships among factors. It should be noted that these relationships do not give a systematic roadmap to act but they show the chain of influences between the factors in the system. These 
research results help us to better understanding the effect of these factors by setting them in a hierarchy structure. The factor "Understanding its tools and techniques" was a significant critical success factor in implementation of LSS, because itwas at the basis of the ISM hierarchy. The studies on the structural model of factors influencing implementation of LSS in Tunisian context are missed. Further, this study provided a hierarchy of variables for implementation of LSS in Tunisian manufacturing organizations which could help all stakeholders for successful implementation of LSS by solving complex issues.

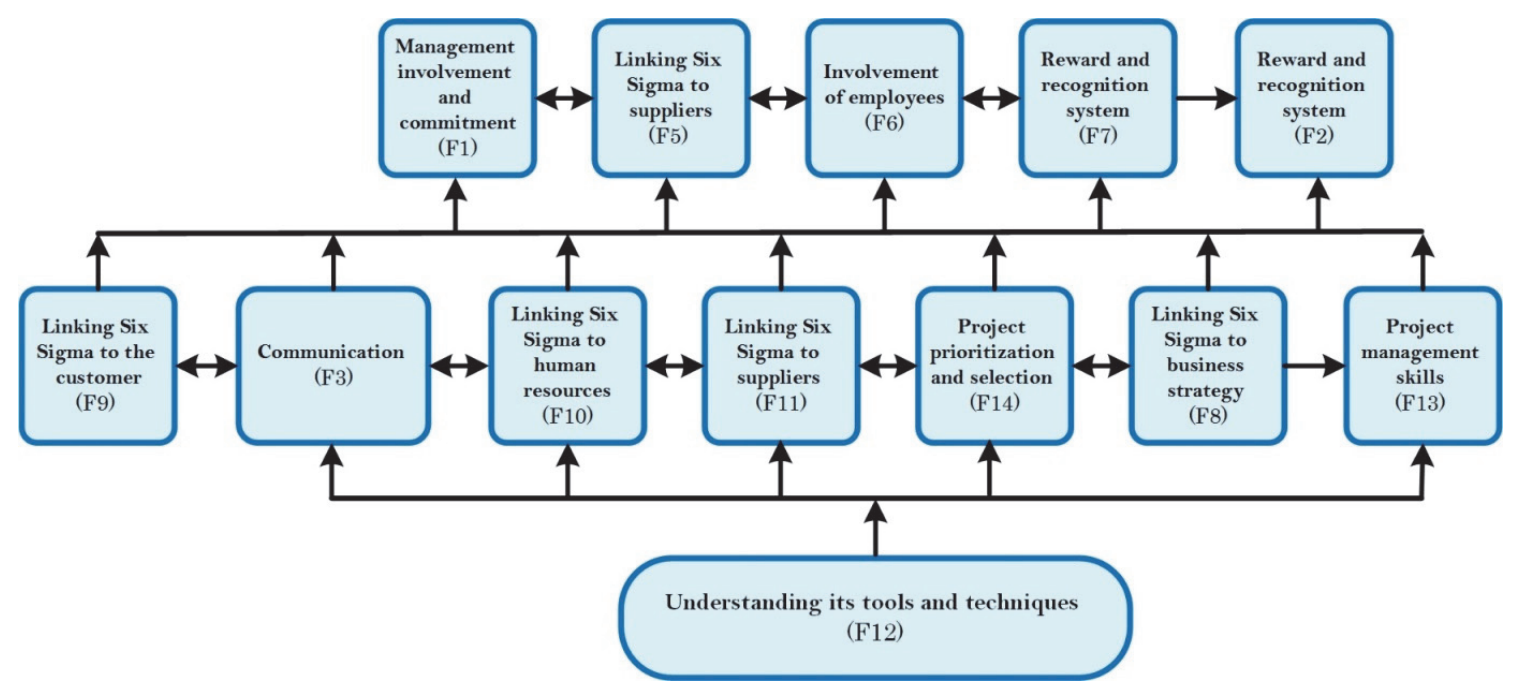

Fig. 2. Interpretive Structural Model for LSS implementation

\section{Micmac analysis and discussion}

The MICMAC analysis is used to analyze the driver power and dependence power of variables. The results of MICMAC analysis complement the ISM hierarchy structure by identifying the driving power and dependence power of each factor. Subsequently, the driving and dependence power diagram is constructed with the input from the total reachability matrix, where taking driving power as horizontal axis and dependence power as vertical axis. Driving power of one element is calculated by adding all the entries in the corresponding row of reachability matrix. Whereas, dependence of one element is obtained by adding all the entries in the corresponding column of reachability matrix. For example, Cultural change (F2) has driving power of twelve and dependence of fourteen. This indicates that this factor influences or drives twelve factors and it is influenced or driven by fourteen factors. The variables are classified into four clusters (Fig.2) according to their driving power and dependence power (Mandal and Deshmukh 1994). These categories are: (1) autonomous factors, that have weak driver power and weak dependence. These factors are generally separated from the system with which they have only few links, which may be strong. There is no autonomous factor in cluster I, which justify judicious selection of barriers in this research, (2) dependent factors, that have weak driver power but strong dependence (cluster II). In this case, Project prioritization and selection (F14) has been categorized as dependent, this factor can be judged as the unfavorable outcome of other factors. They likely should have

lower priorities until the factors they depend on have been attended to. Addressing this final factor more aggressively later in the intervention will improve the organization's efficiency as it forms strong foundations for its activities. (3) linkage factors (cluster III), that have high driving power and high dependence. Fourteen factors are identified to be the linkage variables (F1, F2, F3, F4, F5, F6, F7, F8, F9, F10, F11, F12, F13 and F14). These factors are unstable in the fact that any action on these factors will have an effect on the other factors and also a feedback effect on themselves (Yadav and Barve 2015). This observation indicates that any action directed at these five barriers can affect other barriers, as well as have a feedback influence on themselves. Finally, the factors having high driving power and low dependence are called independent elements (cluster IV). In this case, there are no independent factors. The MICMAC analysis is illustrated in Figure 3. In the obtained results, 13 factors are identified as linkage variables, implying that the relationship between these factors plays an important role in the six sigma implementation. Understanding its tools and techniques (F12) and Project management skills (F13) are relatively more independent, revealing a kind of dominance over other factors in this category. This is reasonably accepted because these two factors have the lowest power-dependence values among all factors. Addressing the effect of factors (F1, F2, F3, F5, F6, F7, F8, F9, F10, F11 and F14), which situated in linkage category and having a high driving and dependence power (Fig.2). These factors are most important,

since they are reactive in nature and form a connection between system input factors and output factors. Such factors are interrelated, and any action of these factors will influence the other factors as well as the whole system. It can be seen that these factors have number links with various factors, but if these variables are not addressed correctly then they will create problems in the implementation of LSS program. 


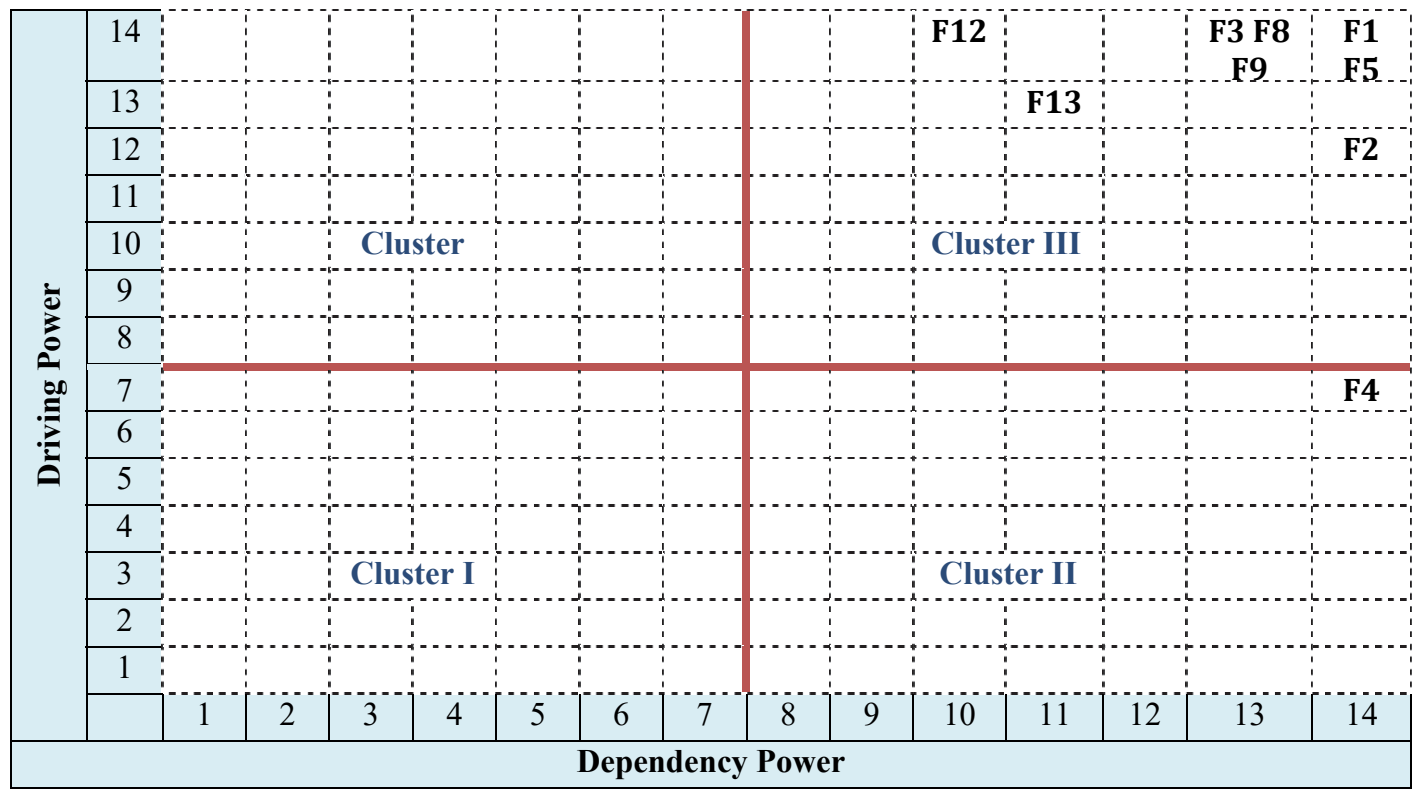

Fig. 3. Driving power and dependence diagram

\section{Conclusion}

In the present investigation, fourteen critical success factors to help promote organizations

to develop Six Sigma were determined through expert inputs and literature survey. These factors may ensure effective LSS implementation and realization of the promised benefits. Factors affecting LSS implementation are complex and abundant.

Data of this study were collected from a sample of Tunisian enterprises and the research model was tested using ISM approach. From this analysis, it was found that the factor of "Understanding its tools and techniques" has been shown to be the extremely important factors for LSS implementation in Tunisian manufacturing. Certain limitations were identified in this research. Firstly, this study was carried out in a developing country like Tunisia, and hence, the outcomes cannot be extrapolated to other topographical regions.

Secondly, in the ISM approach, the inputs or judgments taken from the experts for the development of SSIM and these inputs could be biased influencing the accuracy and reliability of the model. To overcome this limitation, other Multiplecriteria decision making pproaches such as Analytic hierarchy process (AHP) and Analytic network process (ANP). In addition, the ISM model considers only the binary digits, 0 and 1, which are having a limited scope. Hence, this can be solved by considering five-point Likert scale-type measurement. This model can be further tested by factor analysis or hierarchical regression analysis to know more detail about each dimension.

\section{References}

Agi, M. A., \& Nishant, R. (2017). Understanding influential factors on implementing green supply chain management practices: An interpretive structural modelling analysis. Journal of Environmental Management, 188, 351 - 363.

Ahlstrom, P. (1998). Sequences in the implementation of lean production. European Management Journal, 16, $327-334$.

Albliwi, S., Antony, J., \& Lim, S. (2015). A systematic review of lean six sigma for the manufacturing industry. Business Process Management Journal, 21, 665-691.

Antony, J. (2006). Six sigma for service processes. Business Process Management Journal, 12, 234-248.

Antony, J. (2011). Six sigma vs lean: Some perspectives from leading academics and practitioners. International Journal of Productivity and Performance Management, 60, 185-190.

Antony, J., \& Banuelas, R. (2002). Key ingredients for the effective implementation of six sigma program. Measuring Business Excellence, 6, 20-27.

Antony, J., Kumar, M., \& Madu, C. (2005). Six sigma in small- and medium-sized uk manufacturing enterprises: Some empirical observations. International Journal of Quality and Reliability Management, 22, 860-874.

Antony, J., Setijono, D., \& Dahlgaard, J. (2014). Lean six sigma and innovation - an exploratory study among uk organisations. Total Quality Management and Business Excellence, 27, 1-17.

Ben Mabrouk, N. (2020). Interpretive structural modeling of critical factors for buyer supplier partnerships in supply chain management. Uncertain Supply Chain Management, 8(3), 613-626.

Ben Mabrouk, N., Omri, A., \& Jarraya, B. (2020). Factors influencing the performance of supply chain management in saudi smes. Uncertain Supply Chain Management, 8(3), 569-578.

Breyfogle, F. (2003). Implementing Six Sigma: Smarter Solutions Using Statistical Methods. Wiley. 
Brun, A. (2011). Critical success factors of six sigma implementations in Italian companies. International Journal of Production Economics, 131(1), 158 - 164.

Byrne, G. (2003). Ensuring optimal success with six sigma implementations. Journal of Organizational Excellence, 22(2), 43-50.

Chakraborty, A., \& Tan, K. (2007). The current state of six sigma application in services. Managing Service Quality, 17, 194-208.

Chappell, A., \& Peck, H. (2006). Risk management in military supply chains: Is there a role for six sigma?. International Journal of Logistics Research and Applications, 9(3), 253-267.

Choo, A., Linderman, K., \& Schroeder, R. (2007). Method and psychological effects on learning behaviors and knowledge creation in quality improvement projects. Management Science, 53, 437-450.

Coronado, R., \& Antony, J. (2002). Critical success factors for the successful implementation of six sigma projects in organizations. The TQM Magazine, 14, 92-99.

Eckes, G. (2001). The Six Sigma Revolution: How General Electric and Others Turned Process Into Profits. Wiley.

George, M. (2002). Lean Six Sigma: Combining Six Sigma Quality with Lean Production Speed. McGraw-Hill Education.

Gorantiwar, V., \& Shrivastava, R. (2014). Identification of critical success factors for quality-productivity management approach in different industries. International Journal of Productivity and Quality Management, 14, 66 - 106.

Govindan, K., Palaniappan, M., Zhu, Q., \& Kannan, D. (2012). Analysis of third party reverse logistics provider using interpretive structural modeling. International Journal of Production Economics, 140(1), $204-211$.

Hamid, R. A. (2011). Factors Influencing The Success Of Lean Services Implementation: Conceptual Framework. 2nd International Conference on Business and Economic Research (2nd ICBER 2011) Proceeding 2011-272, Conference Master Resources (March).

Harrison, J. (2006). Six sigma vs. lean manufacturing: Which is right for your company?. Foundry Management and Technology, 13, 31-32.

Harry, M. (1998). Six sigma: A breakthrough strategy for profitability. Quality Progress, 31.

Harry, M., \& Schroeder, R. (2005). Six Sigma: The Breakthrough Management Strategy Revolutionizing the World's Top Corporations. Currency.

Henderson, K., \& Evans, J. (2000). Successful implementation of six sigma: Benchmarking general electric company. Benchmarking: An International Journal, 7, 260-282.

Ho, Y.-C., Chang, O.-C., \& Wang, W.-B. (2008). An empirical study of key success factors for six sigma green belt projects at an asian mro company. Journal of Air Transport Management, 14, 263-269.

Hussain, M., Awasthi, A., \& Tiwari, M. K. (2016). Interpretive structural modelinganalytic network process integrated framework for evaluating sustainable supply chain management alternatives. Applied Mathematical Modelling, 40(5), $3671-3687$.

Ingle, S., \& Roe, W. (2001). Six sigma black belt implementation. The TQM Magazine, 13, 273-280.

Jayaraman, K., Teo, L. K., \& Soh, K. L. (2012). The perceptions and perspectives of lean six sigma (lss) practitioners. The TQM Journal, 24, 433-446.

Jeyaraman, K., \& Teo, L. K. (2010). A conceptual framework for critical success factors of lean six sigma: Implementation on the performance of electronic manufacturing service industry. International Journal of Lean Six Sigma, 1, $191-215$.

Knowles, G., Whicker, L., Femat, J. H., \& Canales, F. D. C. (2005). A conceptual model for the application of six sigma methodologies to supply chain improvement. International Journal of Logistics Research and Applications, 8(1), 5165.

Koning, H., Verver, J., Heuvel, J., Bisgaard, S., \& Does, R. (2006). Lean six sigma in healthcare. Journal for healthcare quality : official publication of the National Association for Healthcare Quality, 28, 4-11.

Kwak, Y. H., \& Anbari, F. T. (2006). Benefits, obstacles, and future of six sigma approach. Technovation, 26(5), $708-$ 715.

Laureani, A., \& Antony, J. (2012). Critical success factors for the effective implementation of lean sigma: Results from an empirical study and agenda for future research. International Journal of Lean Six Sigma, 3.

Lyons, A., Vidamour, K., Jain, R., \& Sutherland, M. (2011). Developing an understanding of lean thinking in process industries. Production Planning Control, 24, 1-20.

Majumdar, A., \& Sinha, S. K. (2019). Analyzing the barriers of green textile supply chain management in southeast asia using interpretive structural modeling. Sustainable Production and Consumption, 17, 176 - 187.

Malone, D. W. (1975). An introduction to the application of interpretive structural modeling. Proceedings of the IEEE, 63(3), 397-404.

Mandal, A., \& Deshmukh, S. (1994). Vendor selection using interpretive structural modelling (ISM)." International Journal of Operations \& Production Management, 14(6), 52 - 59.

Oke, S. (2012). Six sigma: Aliterature review. The South African Journal of Industrial Engineering, 18.

Pande, P., Neuman, R., \& Cavanagh, R. (2000). The Six Sigma Way: How GE, Motorola, and Other Top Companies are Honing Their Performance. McGraw-Hill Education.

Piercy, N., \& Rich, N. (2009). Lean transformation in the pure service environment: The case of the call service centre. International Journal of Operations and Production Management, 29.

Prieto-avalos, M., Navarro-gonzález, C., González-Angeles, A., and Medina-león, S. (2014). Reduction waste by combining lean manufacturing and six sigma in an electronics industry. Research Journal of Applied Sciences, Engineering and Technology, 8, 1558-1562. 
Psychogios, A., Atanasovski, J., \& Tsironis, L. (2012). Lean six sigma in a service context: A multi-factor application approach in the telecommunications industry. International Journal of Quality and Reliability Management, 29, 122139.

Raut, R. D., Gardas, B. B., Jha, M. K., \& Priyadarshinee, P. (2017). Examining the critical success factors of cloud computing adoption in the msmes by using ism model. The Journal of High Technology Management Research, 28(2), $125-141$.

Sage, A. (1977). Methodology for large-scale systems. McGraw-Hill.

Sajid, Z., Khan, F., \& Zhang, Y. (2017). Integration of interpretive structural modelling with bayesian network for biodiesel performance analysis. Renewable Energy, 107, 194 - 203.

Sandholm, L., \& Sorqvist, L. (2002). 12 requirements for six sigma success. Six Sigma Forum Magazine, 2.

Scherrer, M., Boyle, T., \& Deflorin, P. (2009). Lean, take two! reflections from the second attempt at lean implementation. Business Horizons, 52, 79-88.

Shah, R., \& Ward, P. (2003). Lean manufacturing: Context, practice bundles, and performance. Journal of Operations Management, 21, 129-149.

Shen, L., Song, X., Wu, Y., Liao, S., and Zhang, X. (2016). Interpretive structural modeling based factor analysis on the implementation of emission trading system in the chinese building sector. Journal of Cleaner Production, 127, $214-$ 227.

Shibin, K., Gunasekaran, A., \& Dubey, R. (2017). Explaining sustainable supply chain performance using a total interpretive structural modeling approach. Sustainable Production and Consumption, 12, $104-118$.

Smith, B. (2003). Lean and six sigma - a one-two punch. Quality Progress, 36, 37-41.

Snee, R. (2010). Lean six sigma - getting better all the time. International Journal of Lean Six Sigma, 1, 9-29.

Wang, F.-K., Du, T., \& Li, E. (2004). Applying six-sigma to supplier development. Total Quality Management and Business Excellence, 15(9-10), 1217-1229.

Warfield, J. (1974). Structuring Complex Systems. Battelle Memorial Institute Columbus, Ohio: The Battelle monograph series. Battelle Memorial Institute.

Wilson, L. (2009). How To Implement Lean Manufacturing. McGraw-Hill Education.

Wyper, B., \& Harrison, A. (2000). Deployment of six sigma methodology in human resource function: A case study. Total Quality Management, 11, 720-727.

Yadav, D. K., \& Barve, A. (2015). Analysis of critical success factors of humanitarian supply chain: An application of interpretive structural modeling. International Journal of Disaster Risk Reduction, 12, 213 - 225.

Zailani, S., \& Sasthriyar, S. (2011). Investigation on the six sigma critical success factors. European Journal of Scientific Research, 57, 124-132.

Zakuan, N., Yusof, S., Laosirihongthong, T., \& Shaharoun, A. (2010). Proposed relationship of tqm and organisational performance using structured equation modelling. Total Quality Management, 21, 185-203.

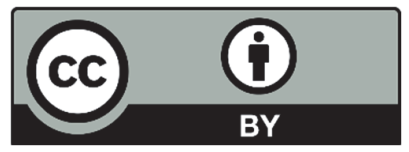

(C) 2021 by the authors; licensee Growing Science, Canada. This is an open access article distributed under the terms and conditions of the Creative Commons Attribution (CC-BY) license (http://creativecommons.org/licenses/by/4.0/). 